\title{
Serum Prolidase Activity, Oxidant and Antioxidant Status in Nonulcer Dyspepsia and Healthy Volunteers
}

\author{
Shweta Kumari, ${ }^{1}$ Akhilesh Kumar Verma, ${ }^{1}$ Sumit Rungta, ${ }^{2}$ Rahul Mitra, \\ Ragini Srivastava, ${ }^{1}$ and Narender Kumar ${ }^{1}$ \\ ${ }^{1}$ Department of Biochemistry, Institute of Medical Sciences, Banaras Hindu University, Varanasi 221005, India \\ ${ }^{2}$ Department of Gastroenterology, Institute of Medical Sciences, Banaras Hindu University, Varanasi 221005, India \\ ${ }^{3}$ Department of Biochemistry, School of Life Sciences, Dr. B. R. Ambedkar University, Agra 282002, India \\ Correspondence should be addressed to Narender Kumar; drkumarn@yahoo.com
}

Received 16 July 2013; Accepted 10 September 2013

Academic Editors: H. Inoue, A. Jiménez, A.-M. Lambeir, F. May, and B. Penke

Copyright (C) 2013 Shweta Kumari et al. This is an open access article distributed under the Creative Commons Attribution License, which permits unrestricted use, distribution, and reproduction in any medium, provided the original work is properly cited.

\begin{abstract}
Helicobacter pylori (H. pylori) infection is associated with increased oxidative stress and serum prolidase activity (SPA) in many diseases. We aimed to observe SPA and oxidative stress in nonulcer dyspepsia (NUD) infected with and without $H$. pylori among eastern Indians. 106 patients with $H$. pylori positive NUD, 82 patients with $H$. pylori negative NUD, and 50 healthy individuals were selected. SPA, total antioxidant capacity (TAOC), and total oxidant status (TOS) were measured with the use of spectrophotometer and an automated measurement method. SPA, TOS, and oxidative stress index (OSI) were significantly higher in patients with $H$. pylori positive than $H$. pylori negative NUD and healthy individuals (all $P<0.0001$ ), whereas TAOC was significantly lower $(P<$ $0.0001)$. Nonsignificant, increased SPA $(P$ value $=0.6083)$ and decreased TAOC $(P$ value $=0.1186)$ were observed in patients with $H$. pylori negative NUD than healthy individuals, while increased TOS and OSI were significant $(P<0.0001)$. Weak, nonsignificant correlations were observed between serum prolidase activity and TAOC, TOS, and OSI in $H$. pylori positive cases. Thus, increased SPA along with increased oxidative stress was observed, which seem to be closely associated with $H$. pylori infection. SPA and oxidative stress seem to be used as biomarkers for $H$. pylori infection in NUD.
\end{abstract}

\section{Introduction}

In 1984, it was first reported that $H$. pylori, a gram negative, spiral shaped, microaerophilic bacterium that colonizes the stomach and is involved in the pathogenesis of duodenal ulceration, gastric cancer, gastric ulceration, and active chronic gastritis $[1,2]$. Dyspepsia is a common term used for abdomen pain and complimented with other gastrointestinal symptoms. Nonulcer dyspepsia is characterized with as upper gastrointestinal symptoms of the patients. Nonulcer dyspepsia is also known as functional dyspepsia which found to be associated with $H$. pylori infection $[3,4]$. H. pylori infection was found to be associated with gastric cancer, peptic ulcer, duodenal ulcer, gastric carcinoma [5-8], and so forth.

Prolidase (EC 3.4.13.9), proline dipeptidase, degraded dipeptides with hydroxyproline or proline as c-terminal amino acid $[9,10]$. It participates in collagen metabolism, cell growth, and matrix remodeling [11]. Its activity has been reported in leukocytes, erythrocytes, plasma, and the various organs such as brain, heart, kidney, uterus, thymus, and dermal fibroblasts. Prolidase activity has been reported in various disorders, like osteoarthritis, chronic liver disease, and osteoporosis [12-15].

H. pylori infection leads to oxidative stress in gastric mucosa [16]. It has been observed that increased oxidative stress associated with gastroduodenal mucosa inflammation in $H$. pylori infected individuals [17]. It has been reported that $H$. pylori infection induced inflammation and can cause gastric atrophy and it is related to increased oxidative stress $[18,19]$. Serum prolidase activity and oxidative status in $H$. pylori infected individuals were studied by Aslan et al. in 2007, among Turkey population [20]. The prevalence of $H$. pylori infection varies from country to country by geographic area, ethnicity, age, race, and socioeconomic status [21, 22] 
and consists of large diversity of strains [22-27]. Due to its different prevalence and diversity of strains, we aimed to observe oxidative stress and serum prolidase activity in patients with $H$. pylori infected nonulcer dyspepsia among Indian subjects. With serum prolidase activity, we also estimated total antioxidant capacity (TAOC), total oxidant status (TOS), and oxidative stress index (OSI) in the above cases.

\section{Material and Methods}

Analytical grade reagents and chemicals were used in this study.

This study was done in the Department of Biochemistry, Department of Gastroenterology, and Department of Pathology, Institute of Medical Sciences, Banaras Hindu University, Varanasi, India. Institutional ethical committee also approved to carry out this study.

2.1. Patients Selection. A total of 238 subjects were selected after informed consent. Out of 238, 188 subjects were patients of nonulcer dyspepsia (NUD) and 50 healthy individuals followed up examination. Among nonulcer dyspeptic patients, $106 \mathrm{H}$. pylori positive and $82 \mathrm{H}$. pylori negative patients were observed. Patients with $H$. pylori positive NUD were considered as cases, while patients with $H$. pylori negative NUD were considered as control-1 group. 50 Healthy individuals were considered as control-2 group. This was done after endoscopy, histopathological examination, and rapid urease test.

2.2. Collection and Storage of Samples. Two antral biopsies were obtained during endoscopy. One was fixed with $10 \%$ formalin for histopathological examination in the Department of Pathology, and the other was treated with $10 \%$ urea solution containing phenol red indicator $(0.2 \%)$ for the rapid urease test. Venous blood was collected in tubes and stored at $4^{\circ} \mathrm{C}$. The serum was separated from the cells by centrifugation at $3000 \mathrm{rpm}$ for $10 \mathrm{~min}$. Serum samples for the measurement of TOS, TAOC, and prolidase activity were stored at $-80^{\circ} \mathrm{C}$ until they were used.

2.3. Histopathological Examination. For histopathological and gastritis scoring standard upgraded Sydney criteria were used [28].

2.4. Rapid Urease Test. Rapid urease test was used to diagnose $H$. pylori infection. Positive rapid urease test indicated $H$. pylori infection, and negative result indicated negative $H$. pylori infection. A positive reaction was dark pink, and a negative reaction was either a yellow or an orange color. The Media consisted of $10 \%$ urea solution $-1.5 \mathrm{~mL}$ and phenol red indicator (0.2\%) - 2 drops, $\mathrm{pH}$ 6.4-6.8.

2.5. Measurement of Total Antioxidant Capacity (TAOC). For measurement of total antioxidant capacity reagent 1 and 2 were prepared. Reagent 1: $3.17 \mathrm{gm}$ of orthodianisidine dihydrochloride and $0.01764 \mathrm{gm}$ of $\mathrm{Fe}\left(\mathrm{NH}_{4}\right)_{2}\left(\mathrm{SO}_{4}\right)_{2} \cdot 6 \mathrm{H}_{2} \mathrm{O}$ were dissolved in $1000 \mathrm{~mL}$ of Clark and Lubs solution; Reagent 2: $0.641 \mathrm{~mL}$ of $\mathrm{H}_{2} \mathrm{O}_{2}$ solution (35\%) was diluted to $1000 \mathrm{~mL}$ with
Clark and Lubs solution. TAOC of serum was measured by the use of an automated measurement method developed by Erel (2004) [29, 30].

2.6. Measurement of Total Oxidant Status (TOS). Reagent 1 and 2 were prepared. Reagent 1: $114 \mathrm{mg}$ of xylenol orange and $8.18 \mathrm{gm}$ of $\mathrm{NaCl}$ were dissolved in $900 \mathrm{~mL}$ of $\mathrm{H}_{2} \mathrm{SO}_{4}$ solution $25 \mathrm{mM}$. The final reagent was composed of $150 \mathrm{mM}$ xylenol orange, $140 \mathrm{mM} \mathrm{NaCl}$, and $1.35 \mathrm{M}$ glycerol, pH 1.75; Reagent 2: $1.96 \mathrm{gm}$ of ferrous ammonium sulfate and $3.17 \mathrm{gm}$ of o-dianisidine dihydrochloride were dissolved in $1000 \mathrm{~mL}$ of $\mathrm{H}_{2} \mathrm{SO}_{4}$ solution $25 \mathrm{mM}$. TOS of serum was measured by a method developed by Erel $(2004)[29,30]$.

2.7. Measurement of Oxidative Stress Index (OSI). Ratio of TOS level to TAOC level was accepted as OSI. OSI values were calculated according to the following formula:

$$
\begin{aligned}
& \text { OSI (arbitrary unit) } \\
& =\frac{\operatorname{TOS}\left(\mu \mathrm{mol} \mathrm{H}_{2} \mathrm{O}_{2}\right. \text { Equiv./L) }}{\text { TAOC }(\mathrm{mmol} \text { Trolox Equiv./L) }}
\end{aligned}
$$

2.8. Determination of Prolidase Activity. Chinard's reagent ( $25 \mathrm{~g}$ of ninhydrin was dissolved in $600 \mathrm{~mL}$ of glacial acetic acid and $400 \mathrm{~mL}$ of $6 \mathrm{~mol} / \mathrm{L}$ orthophosphoric acid at $70^{\circ} \mathrm{C}$ ), standard proline solution $(650 \mu \mathrm{mol} / \mathrm{L}$ solution in $0.45 \mathrm{~mol} / \mathrm{L}$ trichloroacetic acid), and Gly-l-Pro/Sigma Chemical Co. (94 mmol/L in $0.05 \mathrm{~mol} / \mathrm{L}$ Tris $\mathrm{HCl}$ buffer, $\mathrm{pH}$ 7.8, containing $1 \mathrm{mmol}$ of $\mathrm{MnCl}_{2}$ per liter) were prepared and stored at $4^{\circ} \mathrm{C}$.

Plasma was diluted six-fold with buffer mixture containing $0.05 \mathrm{mmol} / \mathrm{L}$ Tris $\mathrm{HCl}$ buffer $(\mathrm{pH} 7.8)$ in $2 \mathrm{mmol}$ of $\mathrm{MnCl}_{2} / \mathrm{L}$ and was incubated for $2 \mathrm{hrs}$ at $37^{\circ} \mathrm{C}$. After incubation, prolidase reaction was initiated by adding $100 \mu \mathrm{L}$ of the preincubated mixture to $100 \mu \mathrm{L}$ of $94 \mathrm{mM}$ Gly-lPro solution. After reaction initiation, it was incubated for $30 \mathrm{~min}$ at $37^{\circ} \mathrm{C}$; reaction was stopped by adding $1 \mathrm{~mL}$ of $0.45 \mathrm{~mol} / \mathrm{L}$ trichloroacetic acid. The released proline was measured by addon of $0.5 \mathrm{~mL}$ of supernatant to $2 \mathrm{~mL}$ of 1:1 mixture of glacial acetic acid:Chinard's reagent and incubated for $10 \mathrm{~min}$ at $90^{\circ} \mathrm{C}$. A blank and standard were run under the same condition. Instead of the supernatant, blank contains $0.5 \mathrm{~mL}$ of $0.45 \mathrm{~mol} / \mathrm{L}$ trichloroacetic acid. The amount of proline was determined by spectrophotometer at $515 \mathrm{~nm}$. Serum prolidase activity was measured by the method developed by Myara et al., 1984 [13].

2.9. Inclusion Criteria. 50 healthy individuals and 188 consecutive patients with nonulcer dyspepsia who agreed to participate in the study were included in our study. Dyspepsia is characterized by upper abdominal pain or discomfort, nausea, vomiting, bloating, or any other symptom related to the upper gastrointestinal tract. Nonulcer dyspepsia was diagnosed when dyspeptic symptoms were present for at least 4 weeks unrelated to exercise for which no organic lesion, such as peptic ulcer, reflux esophagitis, and gallstones, or any systemic disease, was found to be responsible. 
TABLE 1: Histopathological examination of gastritis in cases, control-1, and control-2 (chronic inflammation and intensity of neutrophilic infiltration); for this scoring standard upgraded Sydney criteria were used [28]. No-numbers, \%-percent.

\begin{tabular}{|c|c|c|c|c|c|c|c|c|c|c|c|c|}
\hline \multirow{3}{*}{ Grading index } & \multicolumn{6}{|c|}{ Chronic inflammation } & \multicolumn{6}{|c|}{ Intensity of neutrophilic infiltration } \\
\hline & \multicolumn{2}{|c|}{ For cases } & \multicolumn{2}{|c|}{ For control-1 } & \multicolumn{2}{|c|}{ For control-2 } & \multicolumn{2}{|c|}{ For cases } & \multicolumn{2}{|c|}{ For control-1 } & \multicolumn{2}{|c|}{ For control-2 } \\
\hline & No. & $\%$ & No. & $\%$ & No. & $\%$ & No. & $\%$ & No. & $\%$ & No. & $\%$ \\
\hline Grade 0 & 18 & 17.0 & 82 & 100 & 50 & 100 & 20 & 18.9 & 82 & 100 & 50 & 100 \\
\hline Grade 1 (mild) & 32 & 30.2 & Nil & Zero & Nil & Zero & 30 & 28.2 & Nil & Zero & Nil & Zero \\
\hline Grade 2 (moderate) & 34 & 32.0 & Nil & Zero & Nil & Zero & 36 & 34.0 & Nil & Zero & Nil & Zero \\
\hline Grade 3 (severe) & 22 & 20.8 & Nil & Zero & Nil & Zero & 20 & 18.9 & Nil & Zero & Nil & Zero \\
\hline Total & 106 & 100 & 82 & 100 & 50 & 100 & 106 & 100 & 82 & 100 & 50 & 100 \\
\hline
\end{tabular}

2.10. Exclusion Criteria. The following patients were excluded from our study: patients with coexistent medical illness like chronic heart failure, chronic renal failure, diabetes mellitus, and so forth, pregnant females, patients with continued use of nonsteroidal antiinflammatory drugs, patients with history of use of $\mathrm{H}_{2}$-receptor antagonist/proton pump inhibitors during the previous 3 months, patients with evidence of any organic gastrointestinal/or hepatobiliary diseases (diagnosed by abdominal ultrasound or upper GI endoscopy), patients that their informed consents are not available, and patients who did not agree on followup at the regular interval. Patients with history of alcohol intake and antioxidant supplement consumption were excluded.

2.11. Statistical Analysis. Standard statistical methods were used in this study. Parametric methods were used; a $P$ value of less than $0.05(P<0.05)$ was considered significant. Mean \pm SD was used for data representation. Graph pad and SPSS 16.0 software were used.

\section{Results}

3.1. Chronic Inflammation Grading. Most of cases in our study were of moderate inflammation 34 (32.1\%) on histopathological examination, while mild inflammation was present in $32(30.2 \%)$ cases. 22 cases $(20.8 \%)$ had severe inflammation, while $18(17 \%)$ cases had zero grade inflammation of the gastric mucosa. Grading index for control-1 and control-2 of chronic inflammation was zero (Table 1).

3.2. Activity Grading (Intensity of Neutrophilic Infiltration). Activity is denoted by intensity of neutrophilic infiltration. In our study, most of $36(34 \%) H$. pylori positive subjects show moderate neutrophilic infiltration. While $30(28.2 \%)$, $20(18.9 \%)$, and $20(18.9 \%)$ cases showed mild, severe, and no neutrophilic infiltration activity, respectively. Control-1 and control-2 had zero activity grading (Table 1).

3.3. Serum Prolidase Activity in Cases and Controls. Serum prolidase activity was found to be higher in $H$. pylori positive subjects $\left(37.91 \pm 3.19 \mathrm{mmol} \mathrm{min} \mathrm{m}^{-1}\right)$ as compared to $H$. pylori negative $\left(32.19 \pm 3.43 \mathrm{mmol} \mathrm{min}^{-1} \mathrm{~L}^{-1}\right)$ and healthy subjects $\left(31.92 \pm 3.10 \mathrm{mmol} \mathrm{min} \mathrm{m}^{-1}\right)$. Therefore, serum prolidase activity was significantly higher in cases as compared to controls $(P<0.0001)$. It was observed that control1 had increased serum prolidase activity than control-2, but this was nonsignificant $(P=0.6083)$ (Table 2$)$.

3.4. Total Antioxidant Capacity in Cases and Controls. Total antioxidant capacity (TAOC) in $H$. pylori positive, $H$. pylori negative, and healthy subjects were $1.39 \pm 0.36,1.79 \pm 0.37$, and $1.88 \pm 0.21 \mathrm{mmol}$ Trolox Eq/L, respectively. Thus, the TAOC was statistically lower in $H$. pylori positive cases than controls $(P<0.0001)$. Control-1 had decreased TAOC than control-2, which was nonsignificant $(P=0.1186)$ (Table 2$)$.

3.5. Total Oxidant Status. Total oxidant status (TOS) in cases, control-1, and control-2 were $13.29 \pm 1.29,11.57 \pm 1.06$, and $10.65 \pm 0.21 \mu \mathrm{mol} \mathrm{H}_{2} \mathrm{O}_{2}$ Equiv./L, respectively. Thus, total oxidant status was significantly higher in cases as compared to controls $(P<0.0001)$. Significantly increased TOS was observed more in control-1 than in control-2 $(P<0.0001)$ (Table 2).

3.6. Oxidative Stress Index. OSI was found to be significantly higher in cases $(10.25 \pm 3.12)$ as compared to control-1 (6.71 \pm $1.47)$ and control-2 $(5.72 \pm 0.56)(P<0.0001)$. Increased OSI was observed more in control-1 than in control-2, which was significant $(P<0.0001)$ (Table 2$)$.

3.7. Correlative Observation. Weak, negative, and nonsignificant correlation was observed between serum prolidase activities and TAOC in cases $(r=-0.131, P=0.181)$, while weak, positive, and nonsignificant correlation was observed between serum prolidase activity and TOS and OSI $(r=$ $0.029, P=0.77$, and $r=0.107, P=0.277$, resp.). This above type of weak, nonsignificant correlation was also observed for controls (Table 3).

\section{Discussion}

For gastritis evaluation, upgraded Sydney system was followed [28]. In general, the inflammation induced by $H$. pylori infection has a chronic active gastritis which means that both lymphocytes and neutrophils infiltrate the mucosa in a characteristic manner. Apart from the inflammatory infiltrate, foci of intestinal metaplasia with atrophy, lymphatic aggregates, and lymphoid follicles were formed, and the foveolar 
TABLE 2: Representation of serum prolidase activity, total antioxidant capacity, total oxidant status, and oxidative stress index in the cases, control-1, and control-2. Data is represented as mean \pm standard deviation with their respective units. $P$-value of less than 0.05 showed significant changes. Cases have significantly more increased serum prolidase activity, total oxidant status, and oxidative stress index than control-1 and control-2, while total anti-oxidant capacity significantly decreased.

\begin{tabular}{|c|c|c|c|c|c|}
\hline $\begin{array}{l}\text { Subjects/statistical } \\
\text { parameters }\end{array}$ & $\begin{array}{c}\text { Number of } \\
\text { subjects/condition }\end{array}$ & $\begin{array}{c}\text { Serum prolidase activity } \\
\left(\mathrm{mmol} \mathrm{min}^{-1} \mathrm{~L}^{-1},\right. \\
\text { mean } \pm \mathrm{SD})\end{array}$ & $\begin{array}{c}\text { Total antioxidant } \\
\text { capacity (mmol Trolox } \\
\text { Eq/L, mean } \pm \mathrm{SD})\end{array}$ & $\begin{array}{c}\text { Total oxidant status } \\
\left(\mu \mathrm{mol} \mathrm{H}_{2} \mathrm{O}_{2} \mathrm{Eq} / \mathrm{L},\right. \\
\text { mean } \pm \mathrm{SD})\end{array}$ & $\begin{array}{l}\text { Oxidative stress index } \\
\text { (arbitrary unit, } \\
\text { mean } \pm \mathrm{SD})\end{array}$ \\
\hline Cases & 106 & $37.91 \pm 3.19$ & $1.39 \pm 0.36$ & $13.29 \pm 1.29$ & $10.25 \pm 3.12$ \\
\hline Control-1 & 82 & $32.19 \pm 3.43$ & $1.79 \pm 0.37$ & $11.57 \pm 1.06$ & $6.71 \pm 1.47$ \\
\hline Control-2 & 50 & $31.92 \pm 3.10$ & $1.88 \pm 0.21$ & $10.65 \pm 0.21$ & $5.72 \pm 0.56$ \\
\hline Total & 238 & - & - & - & - \\
\hline \multirow{3}{*}{$\begin{array}{l}P \text {-value } \\
\text { (two-tailed) }\end{array}$} & $\begin{array}{c}\text { Cases versus } \\
\text { control-1 }\end{array}$ & $\leq 0.0001$ & $\leq 0.0001$ & $\leq 0.0001$ & $\leq 0.0001$ \\
\hline & $\begin{array}{c}\text { Cases versus } \\
\text { control-2 }\end{array}$ & $\leq 0.0001$ & $\leq 0.0001$ & $\leq 0.0001$ & $\leq 0.0001$ \\
\hline & $\begin{array}{l}\text { Control-1 versus } \\
\text { control- } 2\end{array}$ & Equal to 0.6083 & Equal to 0.1186 & $\leq 0.0001$ & $\leq 0.0001$ \\
\hline
\end{tabular}

TABLE 3: Representation of correlation of serum prolidase activity and TAOC, TOS, and OSI for the cases, control-1, and control-2. Correlation coefficients of $\leq 0.01$ are considered as significant correlation. Negative sign for correlation coefficients indicated that serum prolidase activity increased with decrease in TAOC in cases, control-1, and control-2, while positive values indicated that serum prolidase activity increased with increase in TOS and OSI in respective cases, control-1, and control-2. In our above correlation study, all correlations have non-significant values.

\begin{tabular}{|c|c|c|c|c|c|c|c|c|c|}
\hline \multirow{2}{*}{$\begin{array}{l}\text { Statistics/correlative } \\
\text { parameters }\end{array}$} & \multicolumn{3}{|c|}{ Serum prolidase activity versus TAOC } & \multicolumn{3}{|c|}{ Serum prolidase activity versus TOS } & \multicolumn{3}{|c|}{ Serum prolidase activity versus OSI } \\
\hline & Cases & Control-1 & Control-2 & Cases & Control-1 & Control-2 & Cases & Control-1 & Control-2 \\
\hline \multicolumn{10}{|l|}{$\begin{array}{l}\text { Pearson correlation } \\
\text { coefficients }\end{array}$} \\
\hline Coefficients, $r$ & -0.131 & -0.013 & -0.170 & 0.029 & 0.093 & 0.029 & 0.107 & 0.087 & 0.152 \\
\hline Sig. (two-tailed), $P$ & 0.181 & 0.907 & 0.238 & 0.770 & 0.407 & 0.840 & 0.277 & 0.437 & 0.292 \\
\hline
\end{tabular}

epithelium was replaced by regenerative epithelium with correspondingly reduced mucus secretion [31]. Because it is found throughout the gastric mucosa from pylorus to cardia, $H$. pylori gastritis is usually pangastritis although in severity it may vary considerably between the antrum and corpus. In the present study, majority of the cases (32.0\%) had moderate inflammation, while mild and severe inflammation was seen in $30.2 \%$ and $20.8 \%$ of cases, respectively. On analyzing activity, mild activity observed in $28.2 \%$ of cases, while $34.8 \%$ and $18.9 \%$ of cases had moderate and severe activity, respectively. $18.9 \%$ of cases had no activity (Table 1), while in control-1 and control-2, zero grading was observed for both chronic inflammation and neutrophilic infiltration. Thus, $H$. pylori infected nonulcer dyspeptic (NUD) patients seem to have more chronic inflammation and neutrophilic infiltration than $H$. pylori negative NUD and healthy subjects.

TOS, TAOC, and OSI are used as biomarkers of oxidative stress and reflect the redox between oxidation and antioxidation [29]. It is well known that oxidative stress can be defined as an increase in oxidants or a decrease in antioxidant capacity, and various oxidants and antioxidants have additive effects on oxidative stress [32]. Although the concentration of plasma level of oxidants and antioxidants can be measured individually, it may not accurately reflect the oxidative status [33-35]. Here, we observed oxidative stress in the study population by using TOS, TAOC, and OSI. TOS in H. pylori infected dyspeptic subjects was found to be higher when compared to $H$. pylori negative subjects with functional dyspepsia and healthy subjects. In Turkey population, TAOC was found to be significantly lower in $H$. pylori positive subjects as compared to control, while oxidative stress index was found to be higher [20]. Among 238 eastern Indian subjects, mean \pm SD of TAOC was found to be significantly lower in $H$. pylori positive subjects as compared to $H$. pylorinegative nonulcer dyspeptic and healthy individuals $(P<$ $0.001)$. Oxidative stress index was found to be higher in cases as compared to controls $(P<0.001)$. Here we observed that in $H$. pylori infected NUD as oxidative stress (TOS, OSI) increases, the TAOC value significantly decreases as compared to $H$. pylori negative NUD and healthy subjects. Thus, $H$. pylori infection associated with increased oxidative stress and decreased antioxidant level in nonulcer dyspeptic patients.

Prolidase enzyme activity had been investigated in various disorders. In subjects with liver disease, serum prolidase activity had been showed to increase especially in early stage of fibrosis. It has been suggested that plasma prolidase activity might be useful to evaluate the fibrotic processes in chronic liver disease in human [36]. A study by Horoz et al. from Turkey represented that serum prolidase activity is to be significantly higher in patients with NASH in comparison to controls $(P=0.016)$ [37]. They also found 
a significant correlation between serum prolidase activity and fibrosis score $(r=0.661, P<0.001)$. Increased serum prolidase activity was well documented in certain cancers like pancreatic cancer, lung carcinoma, breast cancer, Stage 1 endometrial cancer, stomach cancer, ovarian cancer [3840], and so forth. In our study population, increased serum prolidase activity was found in patients with $H$. pylori positive NUD as compared to patients with $H$. pylori negative NUD and healthy subjects. This is comparable with the results of the study of Aslan et al. (2007) [20], who also observed that prolidase activity is to be higher in patients with $H$. pylori positive subjects with mean serum prolidase activity of $44.11 \pm 3.71 \mathrm{U} / \mathrm{L}$ against $39.18 \pm 5.40 \mathrm{U} / \mathrm{L}$ in patients with $H$. pylori negative subjects.

This study concluded that in patients with nonulcer dyspepsia of eastern Indian subjects increased oxidative stress and increased serum prolidase activity may be associated with $H$. pylori infection and their association may help to grant a better understanding regarding the pathogenesis of $H$. pylori infection. Thus, serum prolidase activity may be used as biomarker for $H$. pylori infection in patients with nonulcer dyspepsia. It was also observed that chronic inflammation and neutrophilic infiltration of gastric mucosa are significantly related to $H$. pylori infection in patients with nonulcer dyspepsia.

\section{Conflict of Interests}

The authors declared no conflict of interests.

\section{Authors' Contribution}

Akhilesh Kumar Verma and Shweta Kumari contributed equally to this paper.

\section{Acknowledgments}

The authors thank all the patients who enrolled and gave their consents. They are thankful to Department of Gastroenterology, Department of Pathology, IMS, BHU, Varanasi, for providing necessary facilities to carry out this study. Narender Kumar is gratefully acknowledged; he received grants from Banaras Hindu University, Varanasi, India.

\section{References}

[1] B. J. Marshall and J. R. Warren, "Unidentified curved bacilli in the stomach of patients with gastritis and peptic ulceration," The Lancet, vol. 1, no. 8390, pp. 1311-1314, 1984.

[2] M. J. Blaser, "Hypothesis: the changing relationships of Helicobacter pylori and humans: implications for health and disease," Journal of Infectious Diseases, vol. 179, no. 6, pp. 1523-1530, 1999.

[3] P. Ranjan, "Non-ulcer dyspepsia," Journal of the Association of Physicians of India, vol. 60, pp. 13-15, 2012.

[4] D. K. Mukhopadhyay, R. K. Tandon, S. Dasarathy, M. Mathur, and J. P. Wali, "A study of Helicobacter pylori in north Indian subjects with non-ulcer dyspepsia," Indian Journal of Gastroenterology, vol. 11, no. 2, pp. 76-79, 1992.
[5] S. Tripathi, U. Ghoshal, B. Mittal, D. Chourasia, S. Kumar, and U. C. Ghoshal, "Association between gastric mucosal glutathione-S-transferase activity, glutathione-S-transferase gene polymorphisms and Helicobacter pylori infection in gastric cancer," Indian Journal of Gastroenterology, vol. 30, no. 6, pp. 257-263, 2011.

[6] R. Sotoudehmanesh, A. A. Asgari, H. T. Fakheri, M. Nouraie, M. Khatibian, and N. Shirazian, "Peptic ulcer bleeding: is Helicobacter pylori a risk factor in an endemic area?" Indian Journal of Gastroenterology, vol. 24, no. 2, pp. 59-61, 2005.

[7] Y. Bafandeh, H. Esmaeeli, and S. Aharizad, "Helicobacter pylori infection rates in duodenal ulcer patients in a population with high prevalence of infection," Indian Journal of Gastroenterology, vol. 24, no. 3, p. 130, 2005.

[8] S. Tiwari, U. Ghoshal, U. C. Ghoshal et al., "Helicobacter pyloriinduced apoptosis in pathogenesis of gastric carcinoma," Indian Journal of Gastroenterology, vol. 24, no. 5, pp. 193-196, 2005.

[9] M. Bergmann and J. S. Fruton, "On proteolytic enzymes, XII, regarding the specificity of aminopeptidase and carboxypeptidase, a new type of enzyme in the intestinal tract," Journal of Biological Chemistry, vol. 117, no. 1, pp. 189-202, 1937.

[10] A. Surazynski, W. Miltyk, J. Palka, and J. M. Phang, "Prolidasedependent regulation of collagen biosynthesis," Amino Acids, vol. 35, no. 4, pp. 731-738, 2008.

[11] J. A. Palka and J. M. Phang, "Prolidase activity in fibroblasts is regulated by interaction of extracellular matrix with cell surface integrin receptors," Journal of Cellular Biochemistry, vol. 67, no. 2, pp. 166-175, 1997.

[12] G. Zanaboni, K. M. Dyne, A. Rossi, V. Monafo, and G. Cetta, "Prolidase deficiency: biochemical study of erythrocyte and skin fibroblast prolidase activity in Italian patients," Haematologica, vol. 79, no. 1, pp. 13-18, 1994.

[13] I. Myara, A. Myara, and M. Mangeot, "Plasma prolidase activity: a possible index of collagen catabolism in chronic liver disease," Clinical Chemistry, vol. 30, no. 2, pp. 211-215, 1984.

[14] A. B. Erbağci, M. Araz, A. Erbağci, M. Tarakcioglu, and E. S. Namiduru, "Serum prolidase activity as a marker of osteoporosis in type 2 diabetes mellitus," Clinical Biochemistry, vol. 35, pp. 263-268, 2002.

[15] O. Altindag, O. Erel, N. Aksoy, S. Selek, H. Celik, and M. Karaoglanoglu, "Increased oxidative stress and its relation with collagen metabolism in knee osteoarthritis," Rheumatology International, vol. 27, no. 4, pp. 339-344, 2007.

[16] A. Santra, A. Chowdhury, S. Chaudhuri, J. Das Gupta, P. K. Banerjee, and D. N. Mazumder, "Oxidative stress in gastric mucosa in Helicobacter pylori infection," Indian Journal of Gastroenterology, vol. 19, no. 1, pp. 21-23, 2000.

[17] Y. Naito and T. Yoshikawa, "Molecular and cellular mechanisms involved in Helicobacter pylori-induced inflammation and oxidative stress," Free Radical Biology and Medicine, vol. 33, no. 3, pp. 323-336, 2002.

[18] S. Kato, S. Nakajima, Y. Nishino et al., "Association between gastric atrophy and Helicobacter pylori infection in Japanese children: a retrospective multicenter study," Digestive Diseases and Sciences, vol. 51, no. 1, pp. 99-104, 2006.

[19] R. Srivastava, A. Kashyap, M. Kumar, G. Nath, and A. K. Jain, "Mucosal IgA \& IL-1b in Helicobacter pylori Infection," Indian Journal of Clinical Biochemistry, vol. 28, no. 1, pp. 19-23, 2013.

[20] M. Aslan, Y. Nazligul, M. Horoz et al., "Serum prolidase activity and oxidative status in Helicobacter pylori infection," Clinical Biochemistry, vol. 40, no. 1-2, pp. 37-40, 2007. 
[21] R. E. Pounder and D. Ng, "The prevalence of Helicobacter pylori infection in different countries," Alimentary Pharmacology and Therapeutics, Supplement, vol. 9, supplement 2, pp. 33-39, 1995.

[22] B. S. Ramakrishna, "Helicobacter pylori infection in India: the case against eradication," Indian Journal of Gastroenterology, vol. 25, no. 1, pp. 25-28, 2006.

[23] L. M. Brown, "Helicobacter pylori: epidemiology and routes of transmission," Epidemiologic Reviews, vol. 22, no. 2, pp. 283-297, 2000.

[24] J.-F. Tomb, O. White, A. R. Kerlavage et al., "The complete genome sequence of the gastric pathogen Helicobacter pylori," Nature, vol. 388, no. 6642, pp. 539-547, 1997.

[25] "Helicobacter pylori 26695, complete genome," National Center for Biotechnology Information, 2008, http://www.ncbi. nlm.nih.gov/entrez/query.fcgi? $\mathrm{db}=$ genome\&cmd=Retrieve\& $\mathrm{dopt}=$ Overview\&list_uids $=128$.

[26] "Helicobacter pylori J99, complete genome," National Center for Biotechnology Information, 2008, http://www.ncbi.nlm.nih. gov/entrez/query.fcgi? $\mathrm{db}=$ genome $\& \mathrm{cmd}=$ Retrieve\&dopt $=$ Overview\&list_uids $=139$.

[27] J. D. Oh, H. Kling-Bäckhed, M. Giannakis et al., "The complete genome sequence of a chronic atrophic gastritis Helicobacter pylori strain: evolution during disease progression," Proceedings of the National Academy of Sciences of the United States of America, vol. 103, no. 26, pp. 9999-10004, 2006.

[28] M. F. Dixon, R. M. Genta, J. H. Yardley et al., "Classification and grading of Gastritis: the updated Sydney system," American Journal of Surgical Pathology, vol. 20, no. 10, pp. 1161-1181, 1996.

[29] O. Erel, "A novel automated method to measure total antioxidant response against potent free radical reactions," Clinical Biochemistry, vol. 37, no. 2, pp. 112-119, 2004.

[30] O. Erel, "A new automated colorimetric method for measuring total oxidant status," Clinical Biochemistry, vol. 38, no. 12, pp. 1103-11111, 2005.

[31] M. Stolte and B. Bethke, "Elimination of Helicobacter pylori under treatment with omeprazole," Zeitschrift fur Gastroenterologie, vol. 28, no. 6, pp. 271-274, 1990.

[32] D. D. Wayner, G. W. Burton, K. U. Ingold, L. R. C. Barclay, and S. J. Locke, "The relative contributions of vitamin E, urate, ascorbate and proteins to the total peroxyl radical-trapping antioxidant activity of human blood plasma," Biochimica et Biophysica Acta, vol. 924, no. 3, pp. 408-419, 1987.

[33] T. Miyazawa, "Determination of phospholipid hydroperoxides in human blood plasma by a chemiluminescence-HPLC assay," Free Radical Biology and Medicine, vol. 7, no. 2, pp. 209-217, 1989.

[34] S. B. Sharma, S. Dwivedi, K. M. Prabhu, N. Kumar, and M. C. Baruah, "Preliminary studies on serum lipids, apolipoprotein-b and oxidative stress in xanthelasma," Indian Journal of Clinical Biochemistry, vol. 14, no. 2, pp. 245-248, 1999.

[35] S. B. Sharma, S. Dwivedi, N. Kumar, K. M. Prabhu, and N. Madan, "Studies on oxidative stress, serum iron and iron binding capacity in subjects prone to the risk of coronary artery disease," Indian Heart Journal, vol. 52, no. 5, pp. 583-586, 2000.

[36] I. Myara, A. Myara, and M. Mangeot, "Plasma prolidase activity: a possible index of collagen catabolism in chronic liver disease," Clinical Chemistry, vol. 30, no. 2, pp. 211-215, 1984.

[37] M. Horoz, M. Aslan, F. F. Bolukbas et al., "Serum prolidase enzyme activity and its relation to histopathological findings in patients with non-alcoholic steatohepatitis," Journal of Clinical Laboratory Analysis, vol. 24, no. 3, pp. 207-211, 2010.
[38] J. Palka, A. Surazynski, E. Karna et al., "Prolidase activity disregulation in chronic pancreatitis and pancreatic cancer," Hepato-Gastroenterology, vol. 49, no. 48, pp. 1699-1703, 2002.

[39] M. Cechowska-Pasko, J. Pałka, and M. Z. Wojtukiewicz, "Enhanced prolidase activity and decreased collagen content in breast cancer tissue," International Journal of Experimental Pathology, vol. 87, no. 4, pp. 289-296, 2006.

[40] D. T. Arioz, H. Camuzcuoglu, H. Toy, S. Kurt, H. Celik, and N. Aksoy, "Serum prolidase activity and oxidative status in patients with stage I endometrial cancer," International Journal of Gynecological Cancer, vol. 19, no. 7, pp. 1244-1247, 2009. 

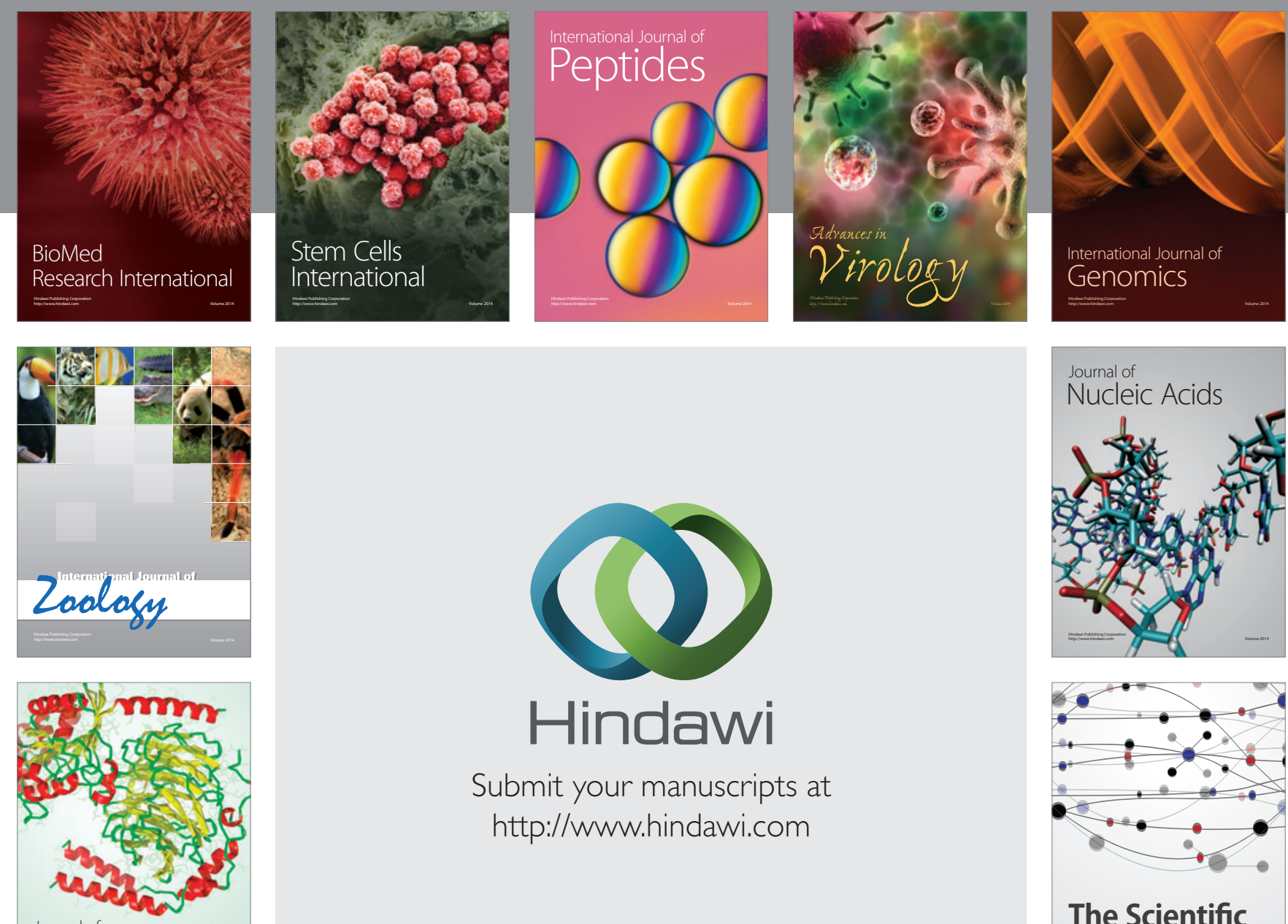

Submit your manuscripts at

http://www.hindawi.com

Journal of
Signal Transduction
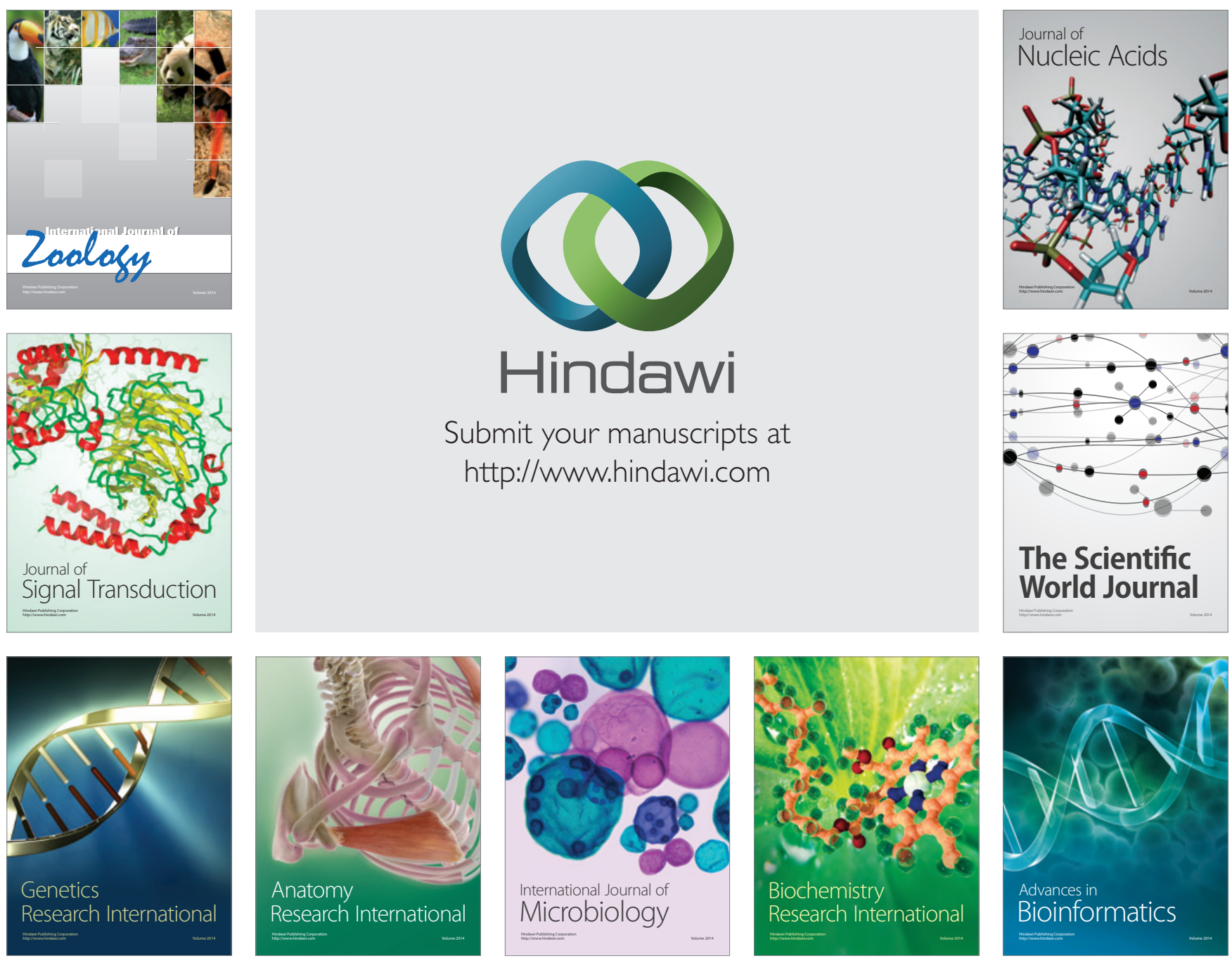

The Scientific World Journal
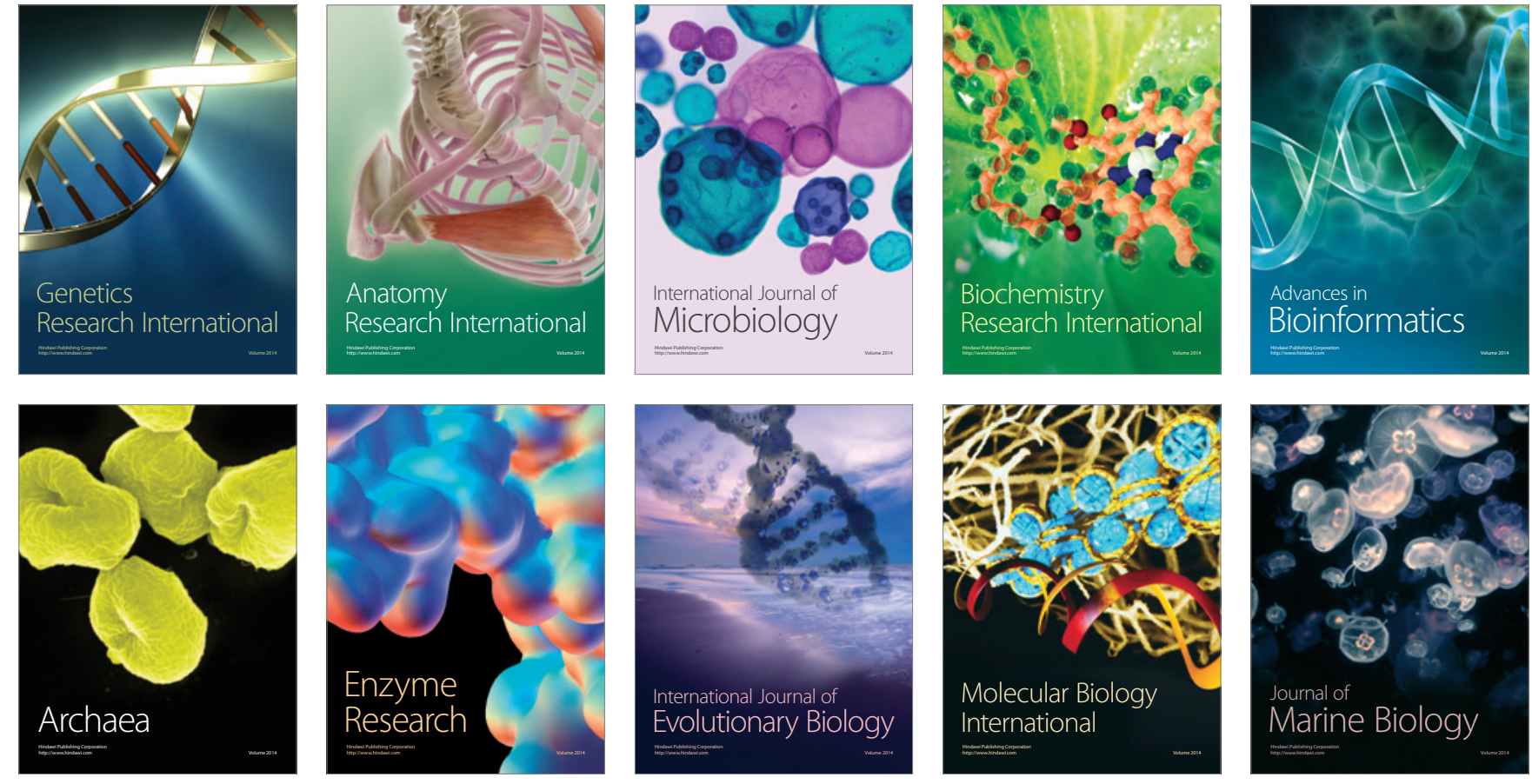